\title{
Stress and aging minimization in photoplastic AFM probes
}

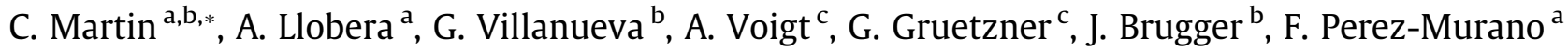 \\ a CNM-IMB, CSIC, Barcelona 08193, Spain \\ ${ }^{\mathrm{b}}$ EPFL, Microsystems Laboratory, Lausanne, CH-1015, Switzerland \\ ${ }^{\mathrm{c}}$ Microresist Technology GmbH Berlin D-12555, Germany
}

\section{A R T I C L E I N F O}

\section{Article history:}

Received 1 October 2008

Received in revised form 4 December 2008

Accepted 10 December 2008

Available online 24 December 2008

\section{Keywords:}

AFM probes

SU-8

Photoplastic

Stress gradient reduction

Polymeric mechanical systems

\begin{abstract}
A B S T R A C T
Photostructurable epoxy based resists, like SU-8, are soft materials with a Young's Modulus around 4 GPa, which makes them particularly suitable as base material to fabricate Atomic Force Microscopy (AFM) probes for non-destructive analysis of fragile samples such as biological materials. In this work, it is shown how by introducing an appropriate processing step consisting of a hard bake, the built-in stress gradient of the final structure was considerably reduced. This improved probes properties such as initial bending and aging and proved the epoxy based resists as good candidates for the low-cost fabrication of micromechanical systems (MEMS) and devices in general.
\end{abstract}

(C) 2008 Elsevier B.V. All rights reserved.

\section{Introduction}

Since its invention in 1986, the atomic force microscope (AFM) has become a revolutionary tool for surface analysis [1]. This has been mainly due to the intensive evolution of equipments and software for AFM operation and data analysis, together with the reliable and precise fabrication of AFM probes which has increased the resolution of the microscopes. Resolution is partially defined by the radius of the probe-tip and, in order to maintain it in a good value, it is required to change probes very often due to the wearing of these tips. For that reason probes are the most important consumable for AFM operation.

AFM probes comprise a cantilever and a tip attached at its free end. The two most commonly used materials for their fabrication are silicon and silicon nitride [2,3]. Standard fabrication processes involve the use of at least three photolithography levels with subsequent etching steps. They yield cantilevers with exceptional mechanical properties as, e.g., a high quality factor (Q) and also with a flat, smooth and reflective surface at the backside suitable for optical detection of cantilever deflections. Although the performance of these probes is very high, a reduction of the fabrication costs would be interesting given the high number of probes that are normally used.

Fully photoplastic probes are one alternative approach to achieve low-cost AFM probes fabrication. Genolet et al. [4] have

\footnotetext{
* Corresponding author. Address: EPFL, Microsystems Laboratory, Lausanne, CH-1015, Switzerland. Tel.: +41216930924.

E-mail address: Cristina.Martin@epfl.ch (C. Martin).
}

already demonstrated the feasibility of such a fabrication process, presenting a reduced number of steps and therefore saving time and reducing cost production. Other authors $[5,6]$ have also studied the advantages of cantilever sensors fabrication based on polymer technology, reaching similar conclusions.

Among the large variety of polymers that are nowadays accessible, the UV-patternable SU-8 epoxy has generated much interest due to its outstanding structural properties, with the possibility of defining ultra-thick geometries with vertical sidewalls (aspect ratios higher than 20:1 are obtained) [7]. The properties of the SU-8 may depend on the processing conditions [8], e.g. if the SU8 is not properly processed after the post exposure bake (PEB), swelling due to humidity and variation of its mechanical properties may occur [9]. The mechanical properties of the SU-8 (concretely the Young's Modulus) have been reported to vary between $4.25 \mathrm{GPa}$ and $6 \mathrm{GPa}[10]$ depending on the cross-linking method (UV or proton beam exposure, respectively). This low Young's Modulus value assures a much higher compliance of the SU-8 structures as compared to an identical silicon counterpart. These factors have favored its application in a large variety of microsystems as valves [11], accelerometers [12], micro-optics [13], or Variable Optical Attenuators [14].

However, for Scanning Probe Microscopy (SPM) applications, in order to have a product that could be able to compete with existing commercial AFM probes, high fabrication yield, low stress gradient, high resolution and long term stability are necessary.

The requirement that AFM probes could be used with most of commercial existing equipment is fulfilled when the cantilever bending is smaller than $1^{\circ}$ angle deflection at the tip, to assure that 
the reflection of the laser will be collected by the photodiode. To obtain straight cantilevers, it is necessary to minimize the stress gradient in the cantilever material.

In the next sections we will present the fabrication process that we have optimized in order to reduce the stress gradient, improve the yield, the resolution and the long term stability, and the results that we have achieved using the fabricated AFM probes.

\section{Fabrication}

The fabrication process of photoplastic probes was based on the multiple spin-coating, exposure and development of a negative tone epoxy based resist on a silicon wafer, being the latter used as a mould for the tip. A double sided polished wafer $(100 \mathrm{~mm}$ diameter) with a thermal oxide layer of $400 \mathrm{~nm}$ was used as a starting substrate. With the first photolithography, apertures were defined in the oxide, which afterwards were used to define inverted pyramids (by means of TMAH wet etching) to be the moulds for the tips [15]. A thermal oxidation $\left(950{ }^{\circ} \mathrm{C}-400 \mathrm{~nm}\right)$ was performed afterwards in order to sharpen the moulds [16], which allowed to obtain probes with smaller tip radius. Once the mould was ready, two successive epoxy based resist layers were deposited and exposed, and they were simultaneously developed. The thickness of these layers can be tuned to obtain the desired cantilever mechanical properties, i.e. elastic constant and resonant frequency, and chip holder features. Typical values were $20 \mathrm{~m}$ for the cantilever and $300 \mathrm{~m}$ for the chip holder. The lengths for the cantilevers were ranged from $100 \mu \mathrm{m}$ to $1050 \mu \mathrm{m}$ (fifteen different lengths), the corresponding theoretical frequencies were from $620 \mathrm{kHz}$ to $5 \mathrm{kHz}$ and the spring constants ranged from $460 \mathrm{~N} / \mathrm{m}$ to $0.4 \mathrm{~N} / \mathrm{m}$. For both layers, the resist used was mr-L 5025 from microresist technology $\mathrm{GmbH}$ although in principle the fabrication process could be used for other epoxy based resist like, e.g., SU-8. To obtain the desired thickness, the resist was spun at different speeds. The exposure doses were taken from the product datasheet depending on the thickness. The post exposure bake (PEB) was performed increasing the temperature (with a ramp of $3{ }^{\circ} \mathrm{C} / \mathrm{min}$ ) from $65^{\circ}$ to $95^{\circ}$ followed by $20 \mathrm{~min}$ at $95^{\circ}$. After the second layer is fully processed (soft baked, exposed and PEB); both layers were developed at the same time in PGMEA (Propylen Glycol Methyl Ether Acetate).

Once the probes were shaped, the two steps left were: hard bake of the wafer and release of the structures. Different options were explored for both in order to minimize the cantilever deflection at the free end and to maximize the yield;

Hard Bake (in a $\mathrm{N}_{2}$ saturated atmosphere): (i) $120^{\circ} \mathrm{C}$ for $1 \mathrm{~h}$; (ii) $120^{\circ} \mathrm{C}$ for $2 \mathrm{~h}$; (iii) $150{ }^{\circ} \mathrm{C}$ for $1 \mathrm{~h}$.

Release of the structure: (iv) HF (49\%); (v) buffered HF solution; (vi) dry release by surface pre-treatment with $\mathrm{C}_{4} \mathrm{~F}_{8}$ [17].

\section{Results}

\subsection{Fabrication yield}

The release of the structures was the fabrication step that determined the fabrication yield, i.e. the percentage of structures that did not break. Dry release method after Teflon-like pre-treatment of the substrate resulted in most of the cases in damaged tips, so this release method was proved to be not valid for AFM probes. Wet etching of the sacrificial layer by means of both HF solution (49\%) and buffered HF solution yielded a similar percentage of cantilevers with tips. Between $70 \%$ and $90 \%$ of the cantilevers were not broken at this step. Selection between both methods was decided on the basis of resulting stress gradient.

\subsection{Stress gradient}

Deflection measurements of all the released cantilevers were taken by means of a confocal microscope, which allows determining the curvature and the deflection angle at the free end. It was observed that under the same fabrication conditions, similar cantilevers released by $\mathrm{HF}(49 \%)$ were deflected one order of magnitude higher than those released by means of buffered HF solution.

As it has been commented, three different hard bakes were performed before release of the fabricated structures. In Fig. $1 \mathrm{a}$ and $\mathrm{b}$ two examples of already released structures are shown. A comparative study of the deflection angle at the free edge for the three different hard bakes (using buffered HF for the release) can be seen in Fig. 1c. It shows that the stress gradient is minimal when the hard bake is at $120^{\circ} \mathrm{C}$ during $2 \mathrm{~h}$ for all the studied range of spring constants, which means that every probe that survived the release step after this hard bake was usable in a commercial AFM.

These two first points determined the total and actual yield of our fabrication process, which for the best option (buffered HF release after a hard bake at $120^{\circ} \mathrm{C}$ during 2 hours) was between $70 \%$ and $90 \%$.

\subsection{Aging study}

It is known that time and environmental changes (temperature, humidity, illumination, etc.) can increase the bending of the polymeric cantilevers, which would represent a huge drawback regarding to the reliability of the product. Therefore, a long term stability study was carried out: we measured along one year the deflection and curvature of a set of the fabricated cantilevers to study the aging. This study was performed keeping the probes under clean room conditions (during approximately 6 months) and then under environmental conditions ( 4 months). In addition, some of them were submitted to a standard international shipment (probes were delivered from Spain to Denmark and then returned back).
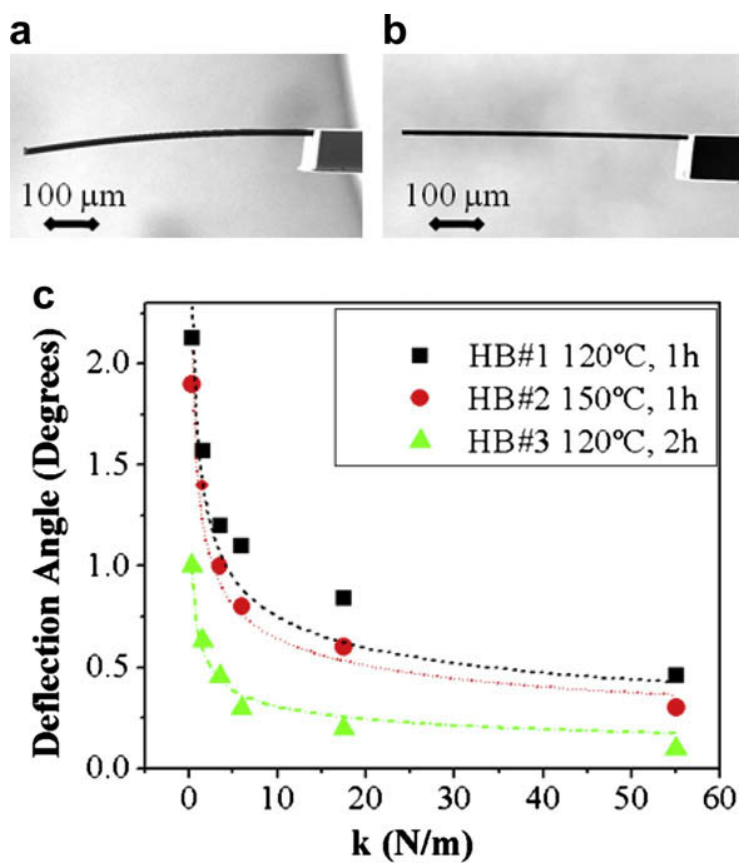

Fig. 1. SEM images of released photoplastic cantilevers after a hard bake process both with the same spring constant $\left(0.7 \mathrm{~N} / \mathrm{m}\right.$ ) at (a) $120^{\circ} \mathrm{C}$ for $1 \mathrm{~h}$ and (b) $120^{\circ} \mathrm{C}$ for $2 \mathrm{~h}$. (c) Initial deflection angle for different hard bakes versus spring constant. The best results are attained with a hard bake at $120^{\circ} \mathrm{C}$ during $2 \mathrm{~h}$. 


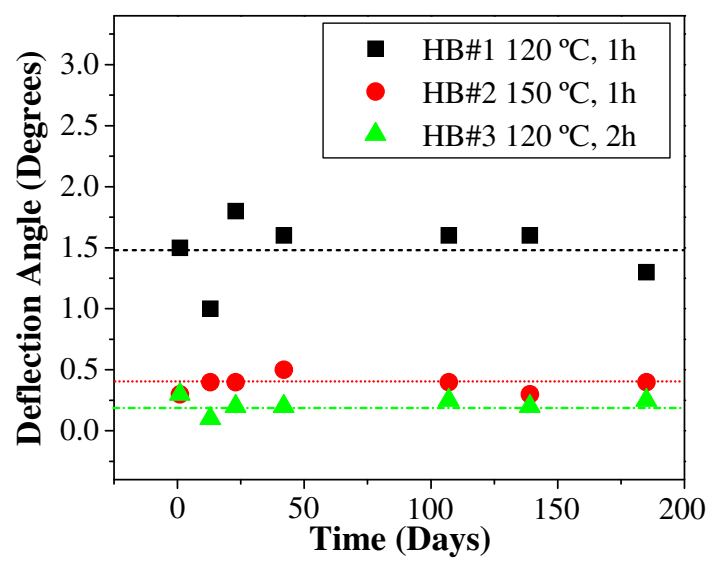

Fig. 2. Aging study of the deflection angle for three cantilevers with the same spring constant $(26 \mathrm{~N} / \mathrm{m})$ processed with the three different hard bakes.

Fig. 2 shows that none of the probes, independently on the PEB conditions used, present a substantial change from their initial deflection. The fluctuations in the measurements are attributed to the intrinsic error of the measurements with the microscope. All the fabricated AFM probes showed a stable stress gradient.

\subsection{Resolution and overall performance}

Once the fabrication of the probes is completed, it is essential to know their general performance in commercial AFM equipment. For that reason, dynamic measurements in air have been performed using a Dimension 3100 (Veeco instruments) and a Cervan-
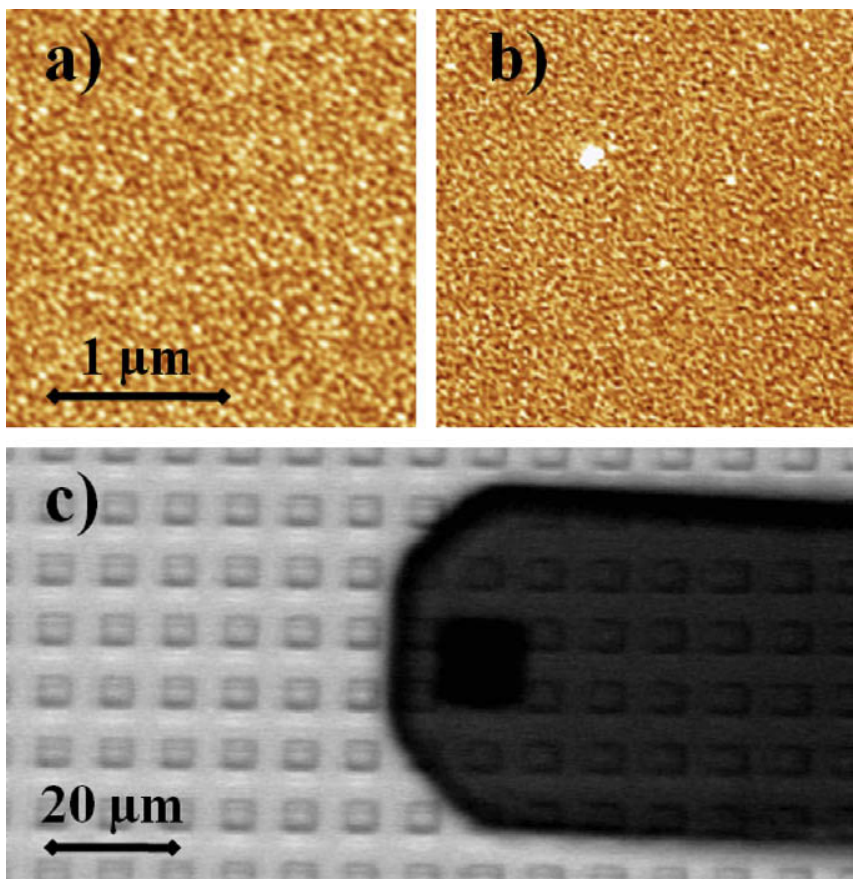

Fig. 3. AFM topography images of a silicon wafer coated with $12 \mathrm{~nm}$ of sputtered aluminium, (a) taken with an epoxy based resist AFM probe with a spring constant of $40 \mathrm{~N} / \mathrm{m}$ and resonance frequency at $123 \mathrm{kHz}$ and (b) corresponds to a silicon commercial AFM probe with a spring constant of $40 \mathrm{~N} / \mathrm{m}$ and a resonance frequency of $265 \mathrm{kHz}$. The resolution in both cases is similar. (c) Optical image of a fabricated photoplastic AFM probe coated with a $20 \mathrm{~nm}$ Au layer to improve reflection while scanning a calibration sample. It can be seen that the lever is transparent enough to see through it to know exactly where the tip is scanning.

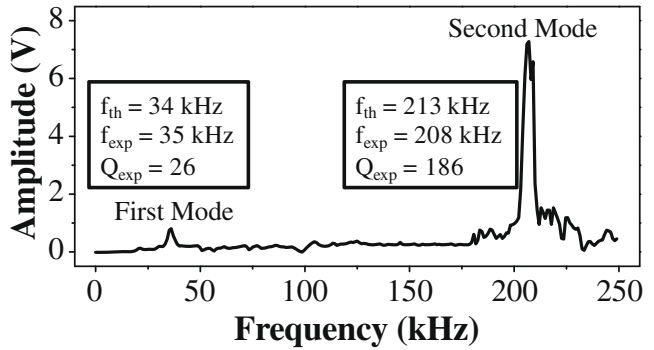

Fig. 4. Frequency spectrum of a photoplastic AFM probe with a spring constant of $8 \mathrm{~N} / \mathrm{m}$. The experimental values match those expected theoretically and the quality factor is increased by a factor $>6$.

tes (Nanotec electronica). All the tested probes could be used in both equipments.

In Fig. 3a and b a comparison between a picture taken with a silicon commercial probe and a photoplastic one is shown. It can be seen that resolution in both cases is pretty similar. As an additional advantage of the photoplastic probes, it can be seen in Fig. $3 \mathrm{c}$ that they can be fabricated being transparent enough to see the sample but reflective enough to scan. The weakest point of these probes is the quality factor which is much higher for the silicon or silicon nitride levers. However, we have also shown the possibility of working using the second harmonic of the photoplastic probes, which gives a much higher quality factor (Fig. 4).

\section{Conclusions}

The possibility of commercializing photoplastic AFM probes has been demonstrated since their fabrication is cost-effective and high yields are achieved. In order to achieve comparable resolution as silicon or silicon nitride commercial tips, a thermal oxidation at $950{ }^{\circ} \mathrm{C}$ is performed to sharpen the moulds and therefore the tips. Flat cantilevers are obtained in a reproducible way by performing a hard bake of a duration of $120 \mathrm{~min}$ at $120^{\circ} \mathrm{C}$ and then releasing the structures by means of wet etching of the oxide sacrificial layer using a buffered HF solution. This initial deflection has been maintained along one complete year, even after keeping the probes in non-controlled environments and delivering them using standard shipping procedures.

\section{Acknowledgments}

This work is supported by 6th FP program project Novopoly (STRP-013619). The authors are very grateful to A. Boisen and M. Lillemose for their collaboration in the aging study of the deflection angle of the cantilevers and to M. Burri and M. Detterbeck (Nanoworld) for their helpful comments.

\section{References}

[1] G. Binnig, C.F. Quate, C. Gerber, Physical Review Letters 56 (9) (1986) 930-933.

[2] T.R. Albrecht, S. Akamine, T.E. Carver, C.F. Quate, Journal of Vacuum Science and Technology a-Vacuum Surfaces and Films 8 (4) (1990) 3386-3396.

[3] O. Wolter, T. Bayer, J. Greschner, Journal of Vacuum Science and Technology B 9 (2) (1991) 1353-1357.

[4] G. Genolet, J. Brugger, M. Despont, U. Drechsler, P. Vettiger, N.F. de Rooij, D. Anselmetti, Review of Scientific Instruments 70 (5) (1999) 2398-2401.

[5] M. Calleja, M. Nordstrom, M. Alvarez, J. Tamayo, L.M. Lechuga, A. Boisen, Ultramicroscopy 105 (1-4) (2005) 215-222.

[6] S. Keller, S. Mouaziz, G. Boero, J. Brugger, Review of Scientific Instruments 76 (12) (2005) 125102

[7] H. Lorenz, M. Despont, N. Fahrni, J. Brugger, P. Vettiger, P. Renaud, Sensors and Actuators A-Physical 64 (1) (1998) 33-39.

[8] J. Zhang, K.L. Tan, G.D. Hong, L.J. Yang, H.Q. Gong, Journal of Micromechanics and Microengineering 11 (1) (2001) 20-26.

[9] R. Feng, R.J. Farris, Journal of Micromechanics and Microengineering 13 (1) (2003) 80-88. 
[10] H. Lorenz, M. Laudon, P. Renaud, Microelectronic Engineering 42 (1998) 371 374.

[11] V. Seidemann, S. Butefisch, S. Buttgenbach, Sensors and Actuators A-Physical 97-8 (2002) 457-461.

[12] A. Llobera, V. Seidemann, J.A. Plaza, V.J. Cadarso, S. Buttgenbach, Journal of Microelectromechanical Systems 16 (1) (2007) 111-121.

[13] A. Llobera, R. Wilke, D.W. Johnson, S. Buttgenbach, IEEE Photonics Technology Letters 17 (12) (2005) 2628-2630.
[14] A. Llobera, G. Villanueva, V.J. Cadarso, S. Buttgenbach, J.A. Plaza, IEEE Photonics Technology Letters 18 (21-24) (2006) 2425-2427.

[15] A. Boisen, J.P. Rasmussen, O. Hansen, S. Bouwstra, Microelectronic Engineering 30 (1-4) (1996) 579-582.

[16] R.B. Marcus, T.T. Sheng, Journal of the Electrochemical Society 129 (6) (1982) $1278-1282$.

[17] D. Haefliger, M. Nordstrom, P.A. Rasmussen, A. Boisen, Microelectronic Engineering 78-79 (2005) 88-92. 